\title{
Interprofessional development in palliative care: cultural humility and a collaborative future for nursing and medicine
}

\author{
William Rosa* \\ Palliative Medicine Fellow, Memorial Sloan Kettering Cancer Center, New York, NY, USA
}

\begin{abstract}
Though the structure and role of a given palliative care team may differ across settings and contexts, the common factors are consistently noted as the involved presence, advocacy, and leadership of nursing and medicine representatives. While much is written about the professional development of nurses and physicians as individual disciplines, little has been explored regarding the interprofessional development possible through shared learning and practice environments in palliative care that celebrate the unique contributions of each. In the end, "working together" is not the same as striving to create a collaborative future. Nursing and medicine are distinct cultures unto themselves. Cultural humility is a concept normally applied to transcultural patient-provider settings, but its core tenets are also capable of informing and expanding collegial engagement. Cultural humility for a truly collaborative future between nursing and medicine in palliative care is one way forward.
\end{abstract}

The World Health Organization (WHO) defines palliative care as "an approach that improves the quality of life of patients and their families facing... life-threatening illness, through the prevention and relief of suffering by means of early identification and impeccable assessment and treatment of pain and other problems, physical, psychosocial and spiritual" [1]. This explanation of palliative care implies that it: (a) is an art and science dependent on advanced clinical knowledge and a human-centered approach to engagement; (b) requires a wide range of scientific and interpersonal expertise, including the abilities to integrate both evidence-based practice and reliable communication skills, and (c) calls for the collaboration of practitioners across professions in order to effectively deliver a wholeperson/whole-family model of care. Though the structure and role of a given palliative care team may differ across settings and contexts, the common factors are consistently noted as the involved presence, advocacy, and leadership of nursing and medicine representatives [2].

While much is written about the professional development of nurses and physicians as individual disciplines [3,4], little has been explored regarding the interprofessional development possible through shared learning and practice environments in palliative care that celebrate the unique contributions of each, and provide opportunities for growth through invitations for transdisciplinary reflection and team building. As a general statement, the idealistic practice of palliative care role models for the healthcare system how to effectively engage in multiprofessional practice in order to deliver whole-person care for patients struggling with advanced serious illness or at end of life. There are potentially influential future implications for palliative care research, practice, education and policy if the specialty were to become firmly rooted in a stance of ongoing interprofessional development. How do palliative care specialists revisit requisite profession-specific competencies, skill building, and disciplinary advancement in true collaboration with their colleagues across the sometimes stagnant and paternalistic aisle? For the purpose of this editorial, collaboration suggests a synergistic experience beyond cooperation, participation and compromise toward a model of caring and respect, where despite differences in background, the unique and valuable contributions of each party are recognized and celebrated as essential [5].

Traditionally, nursing has been viewed as separate from medicine [6]. While this is definitively true in terms of scopes of practice and delineation of clinical privileges, there are deeper distinctions that often prevent the two from co-creating optimal partnerships. For example, the study of medicine has been focused on objectivity, the quantitative aspects of research, external relations inferred by statistical evidence, a fact/data-centered emphasis, the technical validation of knowledge, and paradigm adherence; whereas, particular theoretical frameworks in nursing have tended to shift toward the experiential, more qualitative or mixed methods approach to knowledge development, internal relations confirmed by self and other, an emphasis on meaning, emancipatory approaches to new insights, and paradigm transcendence $[7,8]$. Ultimately, palliative training environments, such as interdisciplinary clinical fellowships, provide a rare opportunity to mend the fences of interprofessional division for the sake of delivering dignified, humancentered care across the spectrum of living and dying.

In the end, "working together" is not the same as striving to create a collaborative future imbued with the qualities mentioned previously. The echoes of interprofessional hierarchy continue to be heard in institutions that do not allow advanced practice nurses to function as chief of a service, present regularly at grand round forums, or lead educational initiatives for staff. However, the movement continues to

Correspondence to: William Rosa, Palliative Medicine Fellow, Memorial Sloan Kettering Cancer Center, New York, NY, USA, E-mail: billyrosa@gmail.com

Received: March 12, 2017; Accepted: March 24, 2017; Published: March 27, 2017 
evolve; parity between the unique and valuable facets of each profession is coming more into the light each day.

Palliative care providers have a responsibility to acknowledge both their inherent cultural arrogance and opportunities to demonstrate cultural humility. Nursing and medicine are distinct cultures unto themselves; professional-cultural norms, values, and ethical positions have defined how each view itself within the healthcare infrastructure and in relation to each other. Cultural humility, first identified by Tervalon and Murray-García, is a concept normally applied to transcultural patient-provider settings, but its core tenets are also capable of informing and expanding collegial engagement [9]. The key attributes of cultural humility promote the practices of openness; self-awareness; surrendering ego; supportive interactions; and selfreflection and critique [10]. Nursing's willingness to be more humble and curious about the worldviews of physician counterparts will, ultimately, allow for healing of the past and present misunderstandings that prevent a collaborative future. The alternative is to become set in a mode of cultural arrogance: the rejection of another's alternative context that ultimately limits understanding, creates barriers for creative solution finding, and generates interprofessional distance making collaboration impossible [10].

This type of evolving relationship is not about talk or theory-it is about action. Actions include not only inquiring about interprofessional colleagues' perspectives on patient scenarios, but also inviting them to share how they arrived at their conclusion and why it matters to them as a palliative care specialist. Remaining authentically present to another, listening, and being willing to accommodate a differing approach is needed now; skills that are often talked about but can be challenging to consistently practice. It takes moral courage to be flexible with the context that one has created of the world, as a person and as a professional, but moral courage is foundational to the nursing profession. After all, we have created the context and it is our choice to allow for its flexibility. Cultural humility allows for an expansion of the nursing paradigm to create an emerging interprofessional context of possibility. It is just one way forward for a truly collaborative future between nursing and medicine in palliative care.

\section{References}

1. World Health Organization (WHO) WHO definition of palliative care. http://www.who int/cancer/palliative/definition/en/

2. Coyle N (2015) Introduction to palliative nursing care. In: Ferrell BR, Coyle N, Paice JA, editors. Oxford Textbook of Palliative Nursing. ( $4^{\text {th }}$ edn.), New York, NY: Oxford University Press, pp. 3-10.

3. Filipe HP, Silva, ED, Stulting AA, Golnik KC (2014) Continuing professional development: Best practice. Middle East Afr J Ophthalmol 21(2): 134-141. [Crossref]

4. Dickerson P, editor. In press. Nursing Professional Development Core Curriculum. $\left(5^{\text {th }}\right.$ edn.), Chicago, IL: Association for Nurses in Professional Development.

5. Hills M, Watson J (2011) Creating a Caring Science Curriculum: An Emancipatory Pedagogy for Nursing. New York, NY: Springer Publishing Company.

6. Rosa W (2014) Nursing is separate from medicine: Advanced practice nursing and a transpersonal plan of care. International Journal for Human Caring 18(2): 76-82.

7. Guba EG, Lincoln YS (1982) Epistemological and methodological bases of naturalistic inquiry. Education, Communication and Technology Journal 30: 233-252.

8. Watson J (2012) Human Caring Science: A Theory of Nursing. ( $2^{\text {nd }}$ edn.), Sudbury, MA: Jones and Barlett.

9. Tervalon M, Murray-García J (1998) Cultural humility versus cultural competence: A critical distinction in defining physician training outcomes in multicultural education. $J$ Health Care Poor Underserved 9(2): 117-125. [Crossref]

10. Soulé I (2016) Flexible and responsive: Applying the wisdom of 'It depends'. In: Rosa W, editor. Nurses as Leaders: Evolutionary Visions of Leadership. New York, NY: Springer Publishing Company, pp. 417-430

Copyright: (C2017 Rosa W. This is an open-access article distributed under the terms of the Creative Commons Attribution License, which permits unrestricted use, distribution, and reproduction in any medium, provided the original author and source are credited. 